\title{
Cleavage Behaviors in Nuclear Vessel Steels
}

Manuscript Completed: September 1994

Date Published: November 1994

Prepared by

G. R. Irwin, X. J. Zhang

Department of Mechanical Engineering

University of Maryland

College Park, MD 20742

Under Contract to:

Oak Ridge National Laboratory

Operated by Martin Marietta Energy Systems, Inc.

Oak Ridge National Laboratory

Oak Ridge, TN 37831-6285

\section{Prepared for}

Division of Engineering

Office of Nuclear Regulatory Research

U.S. Nuclear Regulatory Commission

Washington, DC 20555-0001

NRC Job Code B0119 


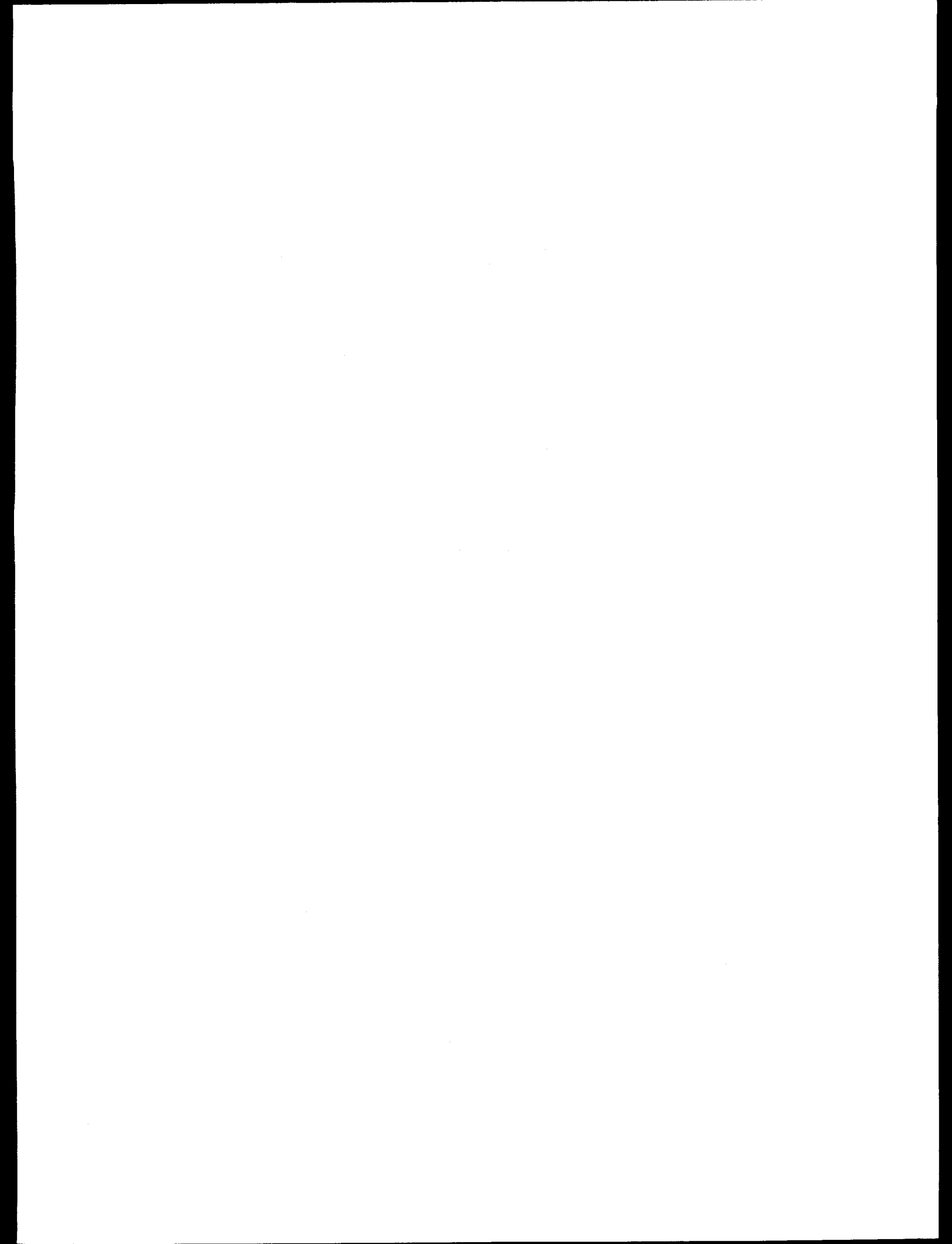




\section{DISCLAIMER}

This report was prepared as an account of work sponsored by an agency of the United States Government. Neither the United States Government nor any agency thereof, nor any of their employees, make any warranty, express or implied, or assumes any legal liability or responsibility for the accuracy, completeness, or usefulness of any information, apparatus, product, or process disclosed, or represents that its use would not infringe privately owned rights. Reference herein to any specific commercial product, process, or service by trade name, trademark, manufacturer, or otherwise does not necessarily constitute or imply its endorsement, recommendation, or favoring by the United States Government or any agency thereof. The views and opinions of authors expressed herein do not necessarily state or reflect those of the United States Government or any agency thereof. 


\section{DISCLAIMER}

Portions of this document may be illegible in electronic image products. Images are produced from the best available original document. 


\begin{abstract}
Cleavage behaviors of nuclear vessel steels in the transition temperature range are reviewed. Viewpoints are presented to assist understanding of cleavage crack speed, cleavage initiation, cleavage arrest, and the sensitivity of fracture
\end{abstract}

Abstract toughness to constraint and temperature. The importance of high local stress elevations by high strain rate is emphasized. This report is designated as HSST Report No. 149. 



\section{Contents}

\section{Page}

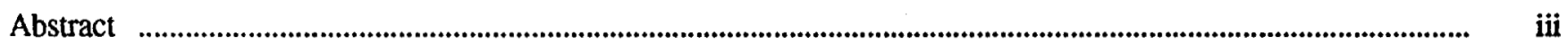

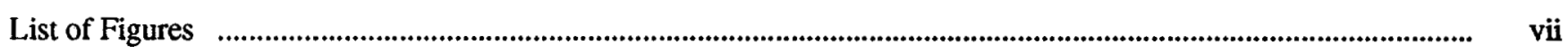

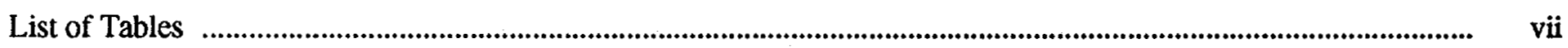

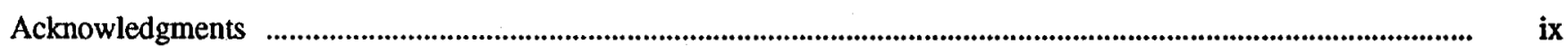

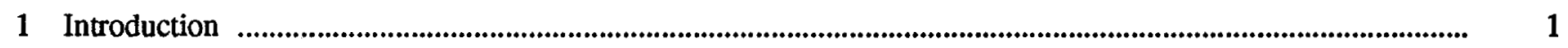

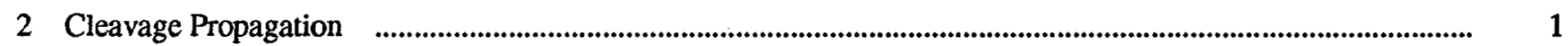

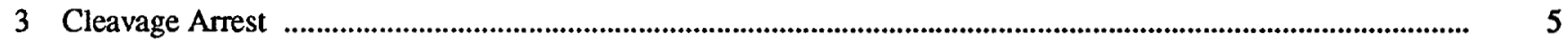

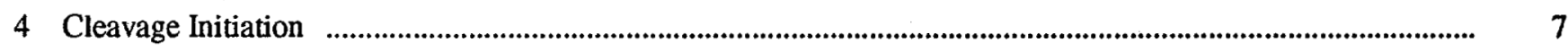

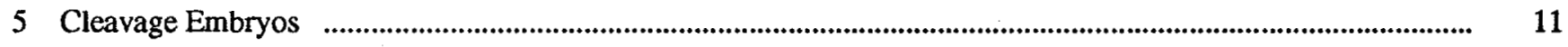

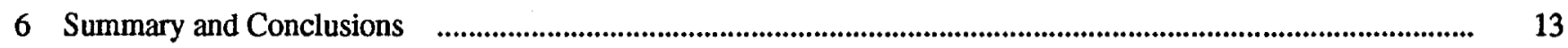

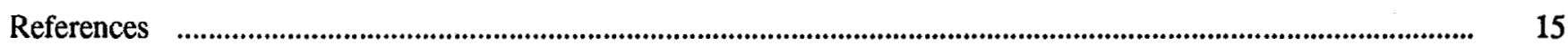




\section{List of Figures}

Figure

Page

1 Regions near front of rapid cleavage crack shown in schematic fashion

2 Section normal to notch in broken CVN specimen showing small arrested cleavage crack

3 (a) Region containing large ferrite grain and (b) region containing final array of cleavage facets

4 Relation of stress to strain rate at given temperatures showing transition between high strain rate regime and low-to-intermediate strain rate regime

$5 \quad \mathrm{~K}_{\mathrm{Ia}}$ as function of temperature from data shown in Fig. 6.1 in Ref. 4

6 (a) Cleavage origin region of ICR found on Charpy specimen of low-carbon weld fractured at $79^{\circ} \mathrm{C}$;

(b) particle fracture and region adjacent to it

7 (a) General view of typical ICR in A 508 steel that started from particle clump; (b) enlargement of box area in (a)

8 Section normal to fracture surface plane of Fig. 6 and $1 \mu \mathrm{m}$ from origin region of cleavage

9 Regions of cleavage initiation at border of fatigue precrack as marked

10 Cleavage initiation region judged likely to be first initiation event

9

11 Schematic pictures of cleavage embryo formation

12 Stress as function of plastic strain rate at several temperatures for $\alpha$-iron

\section{List of Tables}

Table

1 Cleavage embryo size estimates for several values of local stress $\sigma$ and resistance to spreading $R$ 


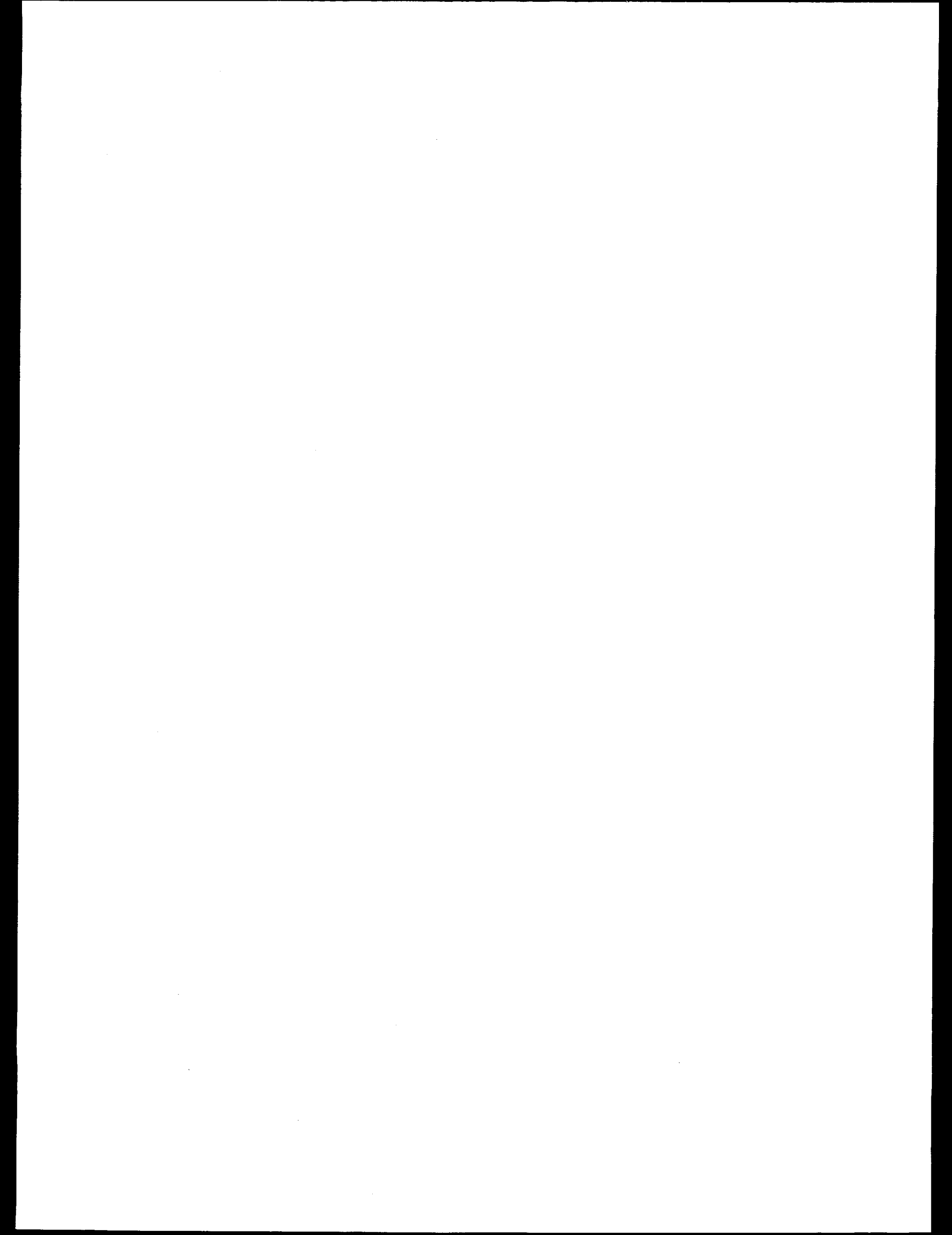




\section{Acknowledgments}

Support for this investigation was provided by Oak Ridge National Laboratory Heavy-Section Steel Technology

Program and by the University of Maryland. Assistance was received from colleagues R. W. Armstrong, J. W. Dally, W. L. Fourney, and C. W. Schwartz. 


\section{Introduction}

To assist understanding and efficient use of fracturetoughness measurements for nuclear vessel steels, a number of fractographic studies have been made. This report discusses cleavage behaviors in the transition temperature range from near nil-ductility transition temperature (NDT) to loss-of-cleavage temperature. In addition, viewpoints are presented which are supported both by what is seen, with scanning electron microscopy (SEM) and optical fractography and by results from theoretical analysis.

\section{Cleavage Propagation}

Figure 1 shows general features of a running cleavage crack in a simplified manner. Although strain rates within the cleavage crack front are too high for significant plastic straining, the strain rates further ahead are lower, permitting an advance plastic zone of moderate size. The smallness of plastic straining in the region containing the cleavage crack "front" is assisted by the diffuse scattering of the partly connected cleavage facets, crudely pictured in Fig. 1. The stretch and rupture of late-breaking connections between cleavage facets are represented by diagonal lines behind the crack front. Essentially the leading cleavage facets rapidly precrack the material ahead, making the separation process rapid.

The varied orientations in an array of connected cleavage facets are illustrated in Fig. 2. In a Charpy specimen of A 508 steel (yield stress $\sigma_{y s}=620 \mathrm{MPa}$ ), broken at room temperature, two cleavage cracks started from the notch. The section plane is normal to the notch. The dominant crack, out of view, stress-relieved and arrested the small crack shown. A light etch was used to indicate microstructure. The main tension direction was apparently altered by the dominant crack so that many of the facets intersect the section plane at small angles, causing apparent opening sizes larger than actual. Although unbroken regions, extending to about $1.5 \mathrm{~mm}$ from the tip of the array, can been seen, all facets are connected at some position forward or behind the section. Enlargements of two areas are shown in Fig. 3(a) and (b). In Fig. 3(a), cleavage on more than one cleavage plane is shown in a large ferrite grain. In the higher magnification views, one can see that the section plane was intersected by some facets that are nearly normal to it. These have a straight-line appearance with no visible indications of plastic deformation.

From other studies, the prior austenite grains ranged in size from $\sim 30$ to $\sim 160 \mu \mathrm{m}$. A picturing of general cleavage in structural steels as a sequence of cleavage bursts, comparable to that size, is not new and seems necessary. Extension velocities of general cleavage in structural steel plates have been measured which range from -180 to $\sim 1700 \mathrm{~m} / \mathrm{s}$ (Ref. 1). From the upper velocity, cleavage must be able to move through a ferrite grain at a velocity above half of shear wave speed, $c_{2}\left(3 \times 10^{3} \mathrm{~m} / \mathrm{s}\right)$. Theoretical studies in Ref. 2 dealt with rapid plastic straining in the plastic zone ahead of a fast-moving cleavage crack tip. The results indicated that, within a small zone enclosing the crack tip, only elastic straining would occur. Using assumptions appropriate for mild steel, the analysis suggested a cleavage crack speed near $0.5 c_{2}$ as likely. Correspondingly, fractographic studies have shown no general plastic strain within cleavage facets other than warping near facet boundaries due to

ORNL-DWG 94M-2968 ETD

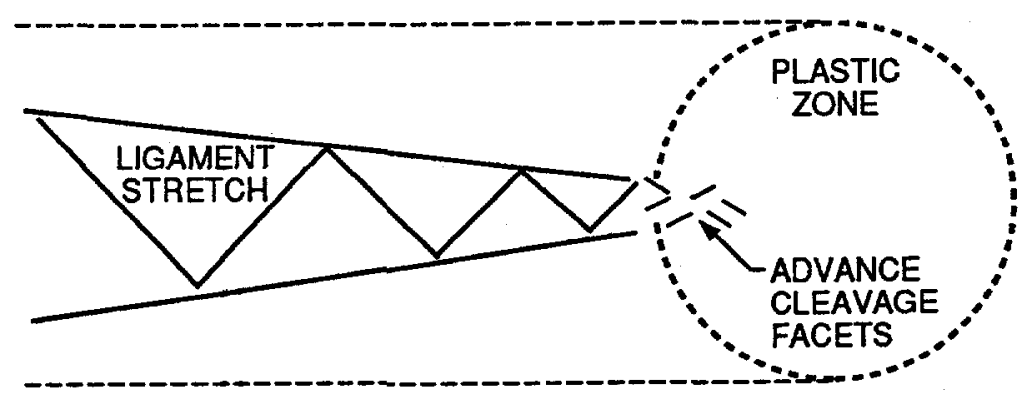

Figure 1 Regions near front of rapid cleavage crack shown in schematic fashion 


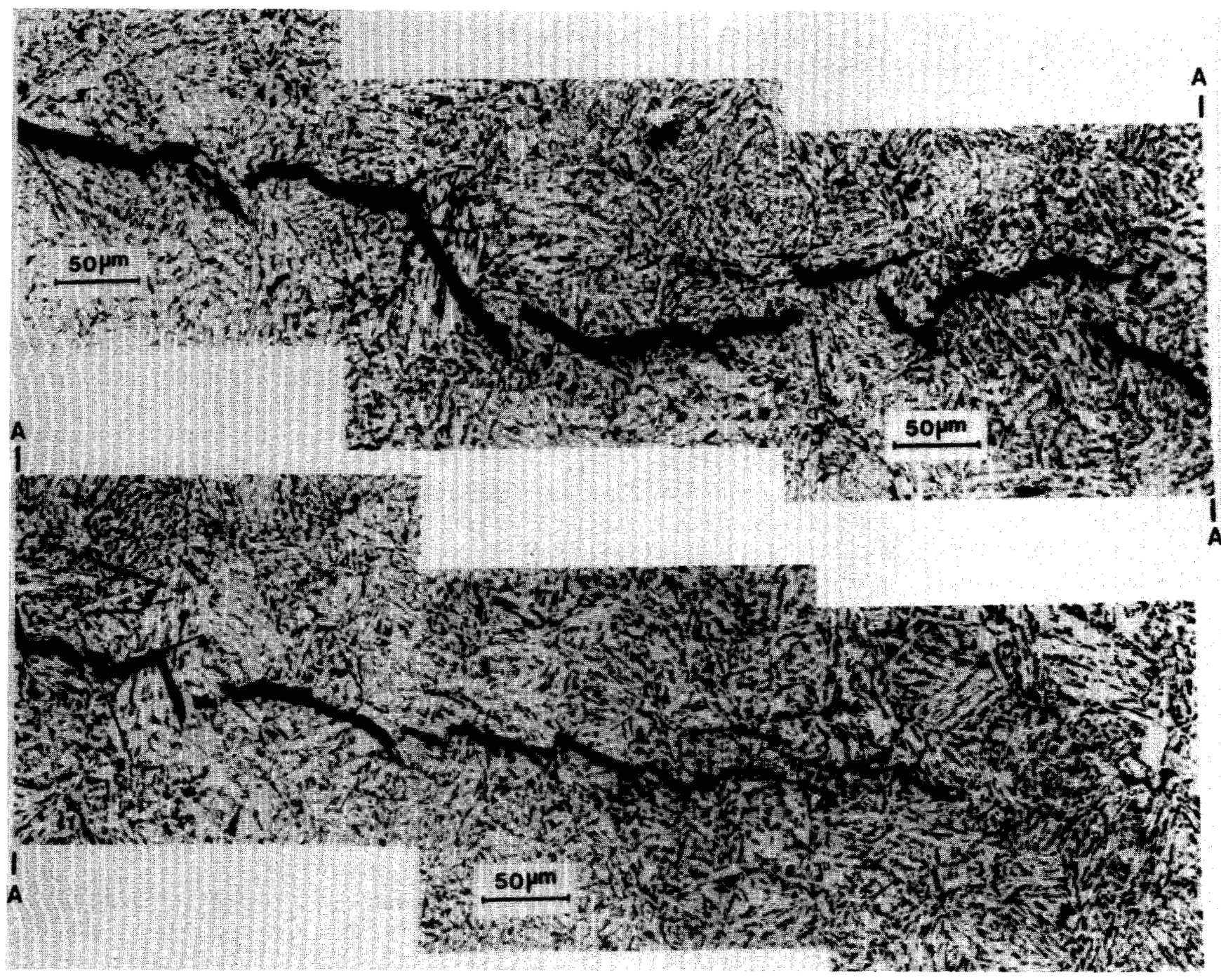

Figure 2 Section normal to notch in broken CVN specimen showing small arrested cleavage crack. The lower view connects to the upper view. The dominant crack is out of view above. This branch crack is connected to the notch $\sim 1 \mathrm{~mm}$ to the upper left; A 508 steel tempered at $613^{\circ} \mathrm{C}$, tested at $-40^{\circ} \mathrm{C}$

postcleavage separation of late-breaking connections. This is observed across the transition temperature range as well as at lower temperatures. Evidently the spreading velocity of cleavage across a ferrite grain is always near or above $0.5 c_{2}$. It seems necessary therefore to picture general cleavage as a sequence of quick local bursts of cleavage separated by time periods of "pause." With this assumption, conditions that lower the extension speed, decrease driving force, or increase plate temperature can do that by lengthening the "pause" times.
If we assume that the time needed to advance the crack front by a distance comparable to average prior austenite grain size is the time for the run-arrest burst plus the pause time $\left(t_{p}\right)$, then

$$
t_{p}=\frac{L}{C}-\frac{L}{C_{f}}
$$

where $L$ is the size of an average rum-arrest burst $(100 \mu \mathrm{m})$, $C$ is the general cleavage crack speed, and $C_{f}$ is the crack 
ORNL-PHOTO 2615-94

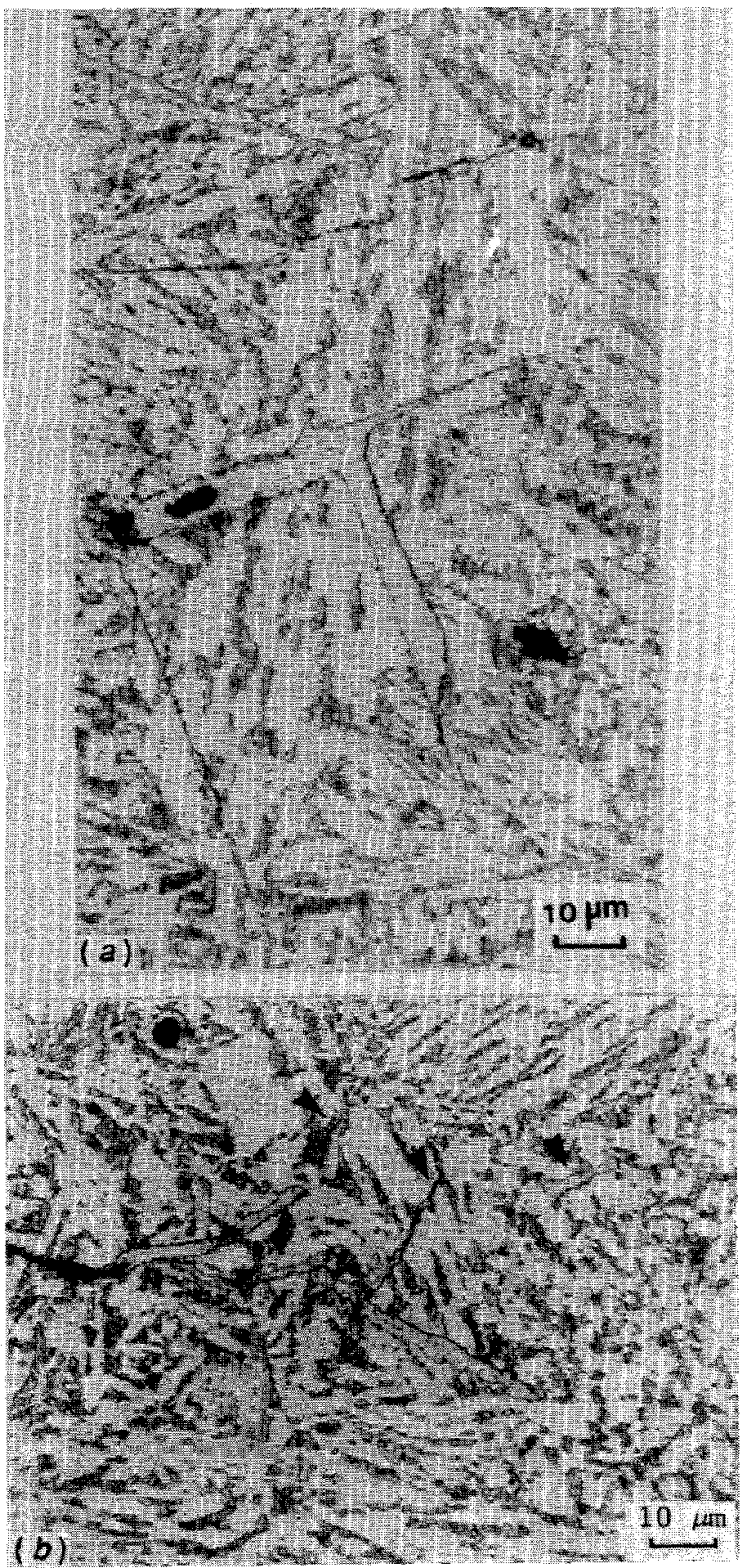

Figure 3 (a) Region containing large ferrite grain and (b) region containing final array of cleavage facets speed through ferrite grains. A rough estimate of maximum pause time is obtained if we assume that $C_{f}$ is half of shear wave speed and that $C$ is $200 \mathrm{~m} / \mathrm{s}$, the lowest observed cleavage velocity before crack arrest. From these assumptions, the pause times near crack arrest are no larger than $0.5 \mu \mathrm{s}$, and a small strain of $1 \%$ corresponds to a strain rate above $2 \times 10^{4} / \mathrm{s}$. Figure 4, from Ref. 2 , indicates that an increase of strain rate above $2 \times 10^{4} / \mathrm{s}$ is accompanied by rapid increase of resistance to plastic straining. Evidently the strain rates of main interest for run-arrest cleavage behaviors in steels are entirely above $10^{4} / \mathrm{s}$, a region where the sensitivity of plastic flow stress to strain rate is relatively high.

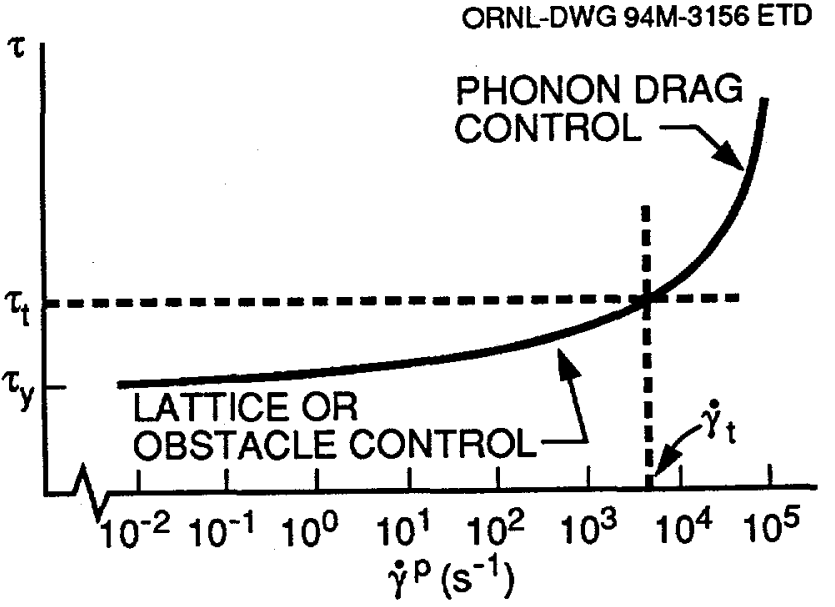

Figure 4 Relation of stress to strain rate at given temperatures showing transition between high strain rate regime and low-tointermediate strain rate regime. Source: Ref. 2 



\section{Cleavage Arrest}

In small-specimen wedge-loaded tests for crack-arrest $\mathrm{K}_{\mathrm{Ia}}$ values, rapid stress wave damping and the relatively small specimen size limit the dynamic stress elevation following crack arrest to an unimportant size. When the specimen is heat-tinted, chilled, and broken open, no indication of a crack front stretch zone is visible. When the test specimen is large, a substantial amount of dynamic reloading may occur. The postarrest plastic straining will then produce a crack-front stretch zone and may reinitiate cleavage. In the wide-plate tests at the National Institute of Standards and Technology (NIST), a series of cleavage arrests occurred; each was followed by plastic stretch at the crack front and reinitiation of cleavage. The $\mathrm{K}$ for reinitiation was computed using a dynamic calculation fitted to the time and crack-position observations at the end point of the arrest period. The $K$ value for cleavage arrest was the lower value of $\mathrm{K}$ at the beginning of the crack-arrest time period. The reloading time leading to reinitiation was rather small. The time values listed in Ref. 3 ranged from 1 to $10 \mathrm{~ms}$.

However, for the abrupt crack-arrest event, a time longer than $10 \mu$ s would be unlikely.

Figure 5 from Ref. 4 shows a collection of values of crackarrest toughness, $\mathrm{K}_{\mathrm{la}}$, obtained with small test specimens and with thermal-shock loadings of large cylinders. These results do not show a significant influence of constraint upon the $\mathrm{K}_{\mathrm{Ia}}$ value. This is quite plausible because the stress elevation by constraint is associated with plastic yielding. The times closely associated with the crack-arrest event are too small to permit a significant amount of plastic straining.

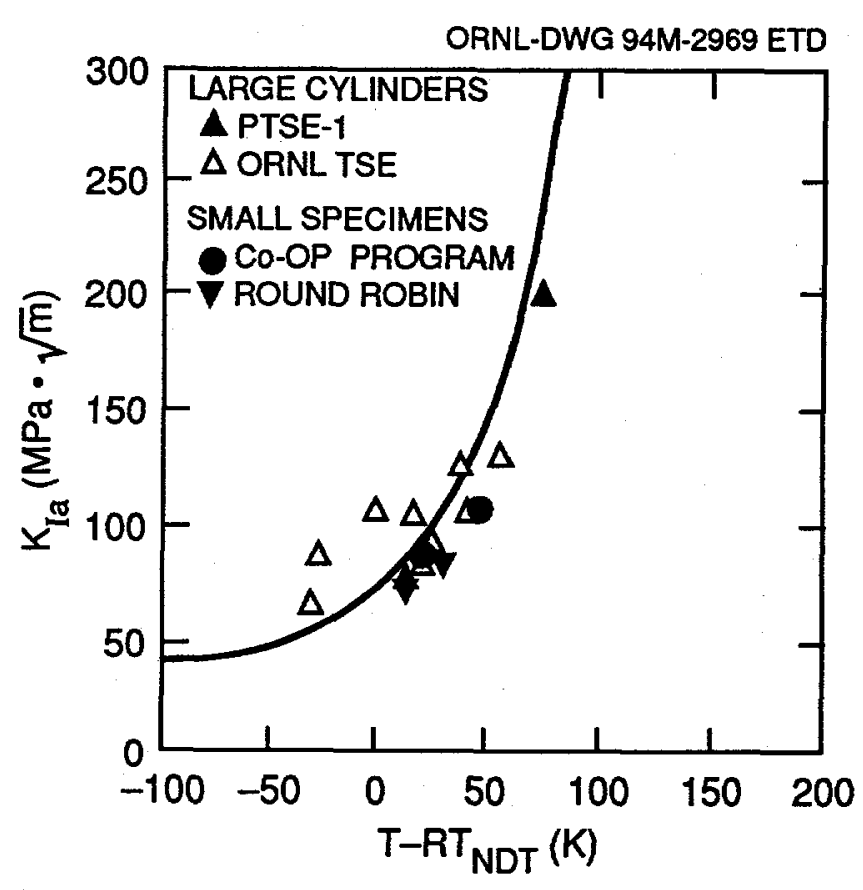

Figure $5 \quad \mathrm{~K}_{\mathrm{Ia}}$ as function of temperature from data shown in Fig. 6.1 in Ref. 4 


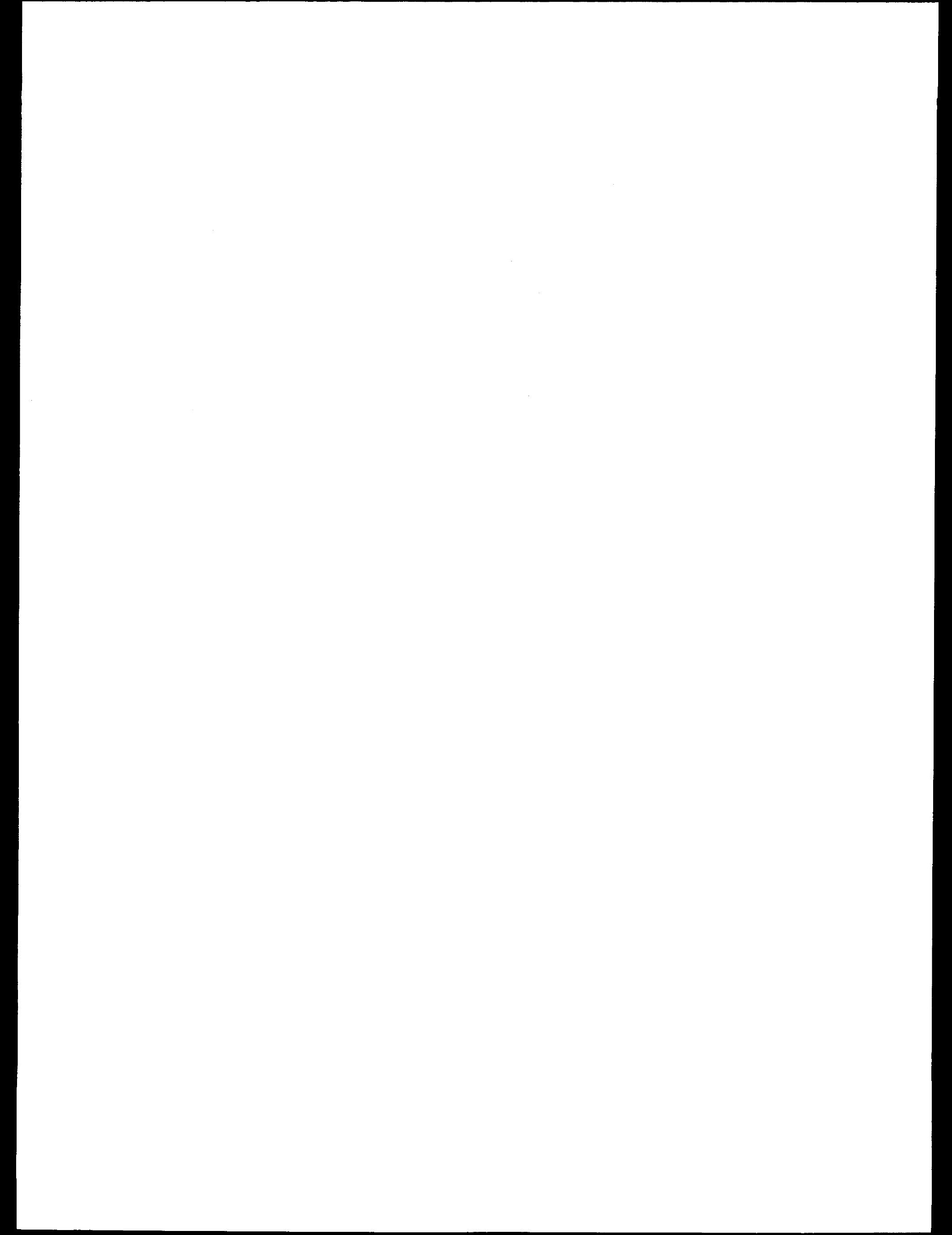




\section{Cleavage Initiation}

Initiation of a general cleavage event differs importantly from crack arrest because the loading rate, before onset of cleavage, permits various degrees of plastic flow stress elevation by constraint (above quasi-static values), which can be estimated in macroscopic fashion using elasticplastic calculations. As will be illustrated, cleavage initiation occurs only when rapid separations of certain features of microstructure induce a very large elevation of strain rate and tension within a micron-size region. Several features of microstructure, associated with cleavage initiation, have been noted ${ }^{5-7}$ and will be briefly reviewed. In heavy-section nuclear vessel steels and their weld metals, rapid hole-joining fractures, produced at temperatures close to and above loss-of-cleavage temperature, contained small islands of cleavage. From fractographic studies, each of these seemed to have a single origin location from which cleavage spread through a number of ferrite grains without visible indications of arrest at the ferrite boundary passageways. These isolated cleavage regions will be termed ICRs.

In the low-carbon weld metals, the spreading of cleavage emanated either from a broken silicate particle in the 2- to 3- $\mu \mathrm{m}$ size range or from a "clump" of smaller silicate particles that debonded. Figure 6(a) shows SEM views of an ICR containing a particle fracture cleavage origin in weld metal. Figure $6(b)$ shows the cleavage surface region, adjacent to the particle fracture, within which cleavage initiated and spread. Reference 5 estimated a plausible strain rate in the ferrite close to the particle crack as about $10^{6} / \mathrm{s}$. From other studies, ${ }^{2}$ plastic strain rates that high can elevate tensile stress to values near $E / 40$, where $E$ is the elastic modulus.

All of the cleavage initiation sites identified in A 533 B and A 508 steels were associated with groups of debonded carbide particles that we termed particle "clumps;" the particles were small, 0.1 to $0.2 \mu \mathrm{m}$. Figure 7 shows general views of a typical ICR in A 508 steel. Figure 8 shows a section nearly normal to the cleavage fracture through the initiation region. Portions of the clump of cavities, from which cleavage spread, are barely visible about $1 \mu \mathrm{m}$ behind the section plane. The appearance of debonding beneath the fracture surface is of special interest. Some of the particles are visible within cavities, which were incompletely joined when deformation was arrested by rapid cleavage above them. This section view indicates that particle debonding, when forced by a high local stress, can be very rapid. Progressive debonding is the expected behavior when particle debonding forms a cavity. This is supported by the adhesion with which a particle clings to the "bottom" of a cavity. It is suggested that, near the front of a rapid debonding separation, strain rate and stress can
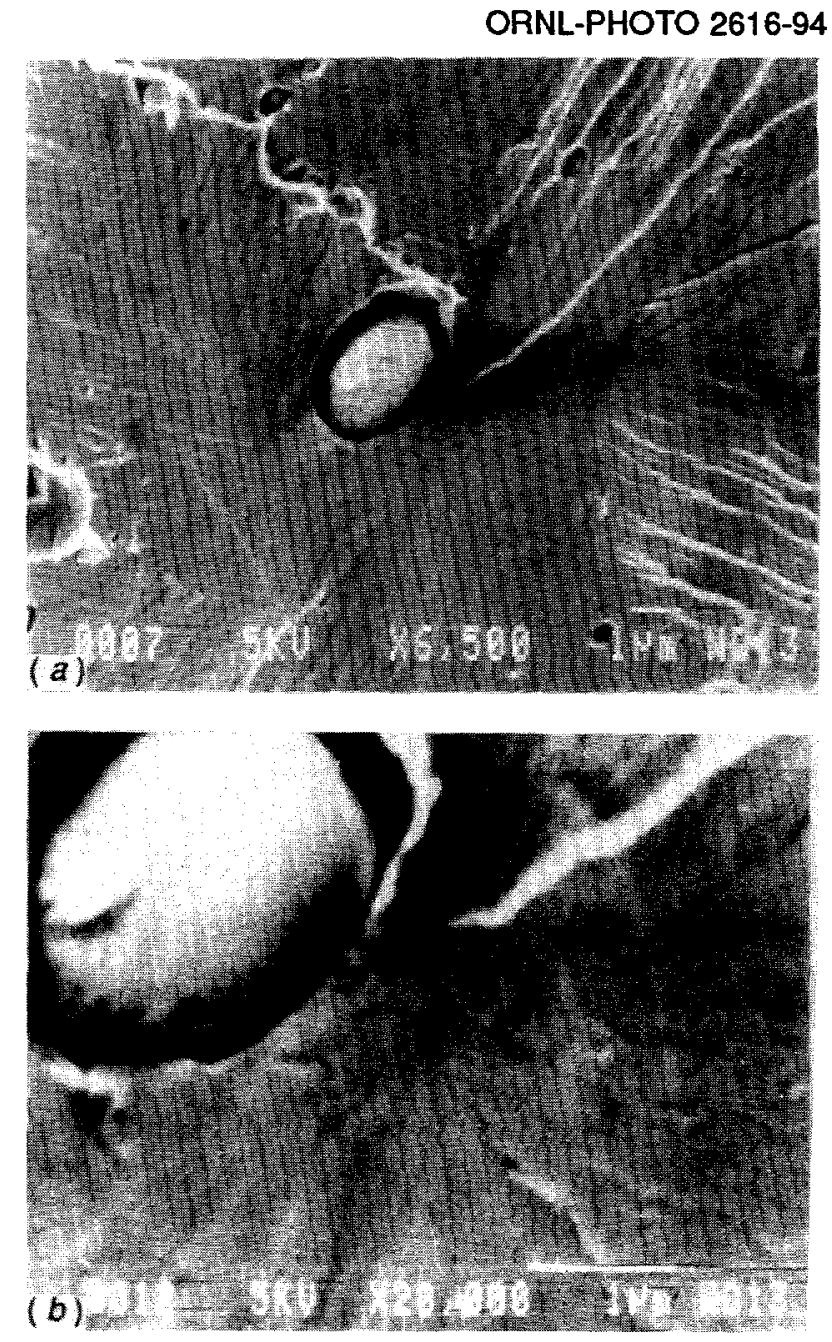

Figure 6 (a) Cleavage origin region of ICR found on Charpy specimen of low-carbon weld fractured at $79^{\circ} \mathrm{C} ;(b)$ particle fracture and region adjacent to it

be elevated to the same high levels as would pertain near a rapid particle fracture.

The investigations of cleavage initiation at temperatures below loss-of-cleavage temperature centered attention on A 508 steel at temperatures near to and moderately below reference nil ductility transition temperature (RT $\left.{ }_{N D T}\right)$. The yield strength was $620 \mathrm{MPa}$ (90 ksi), and the RT $\mathrm{NDT}$ was near $60^{\circ} \mathrm{C}$. Figure 9 shows a region within which cleavage started in pop-in fashion from a fatigue precrack. A large number of closely spaced cleavage initiations occurred along the border of the fatigue precrack. Although independent (nearly simultaneous) initiations are possible, most of these indications of cleavage initiation occurred by rapid reinitiations, spreading in lateral fashion from a first- 


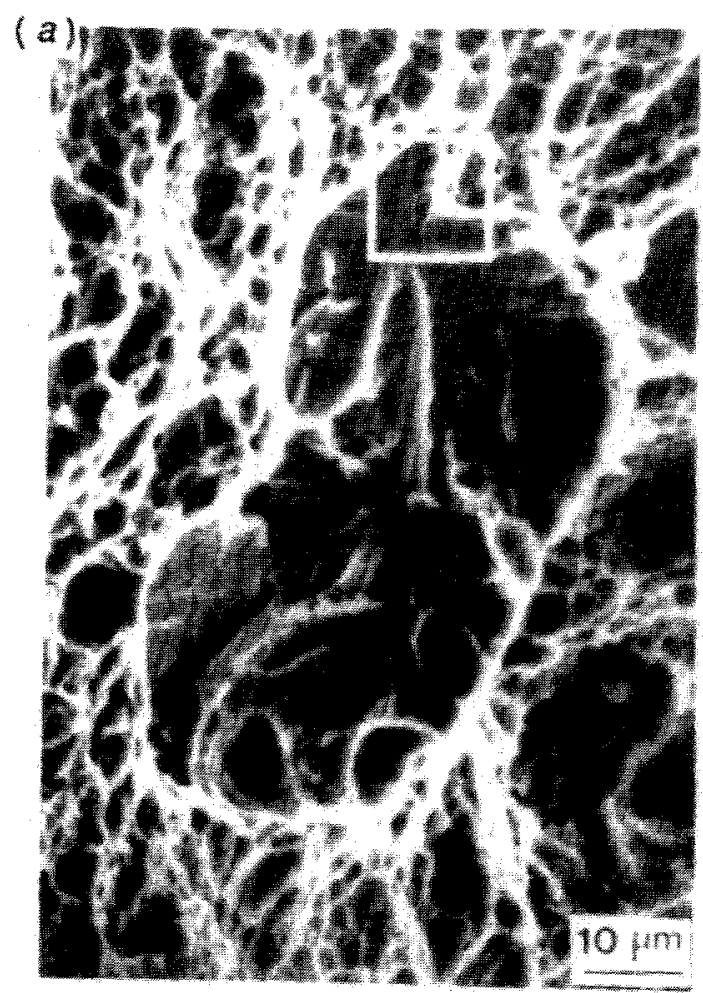

0
0
5
2

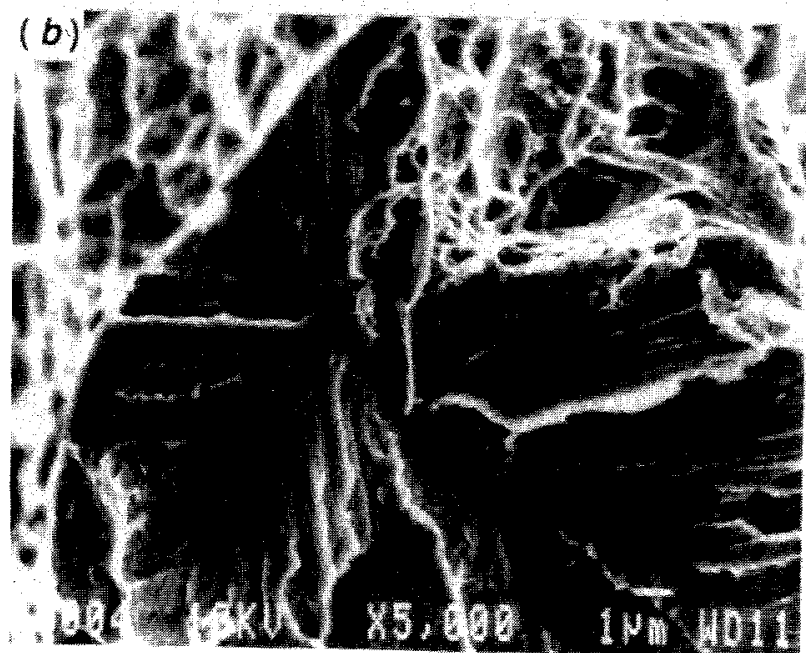

Figure 7 (a) General view of typical ICR in A 508 steel that started from particle clump; (b) enlargement of box area in (a)

cleavage event. Positions of cleavage initiation and the estimated extent of the pop-in event are marked on the figure. Obviously lateral spreading is more rapid than spreading in the forward direction. This pattern is favored by the stress elevation near the precrack. Figure 10 shows the cleavage initiation site that was selected as the probable start of the pop-in event. At the location of this event, the forward extension of the pop-in was largest. Debonding

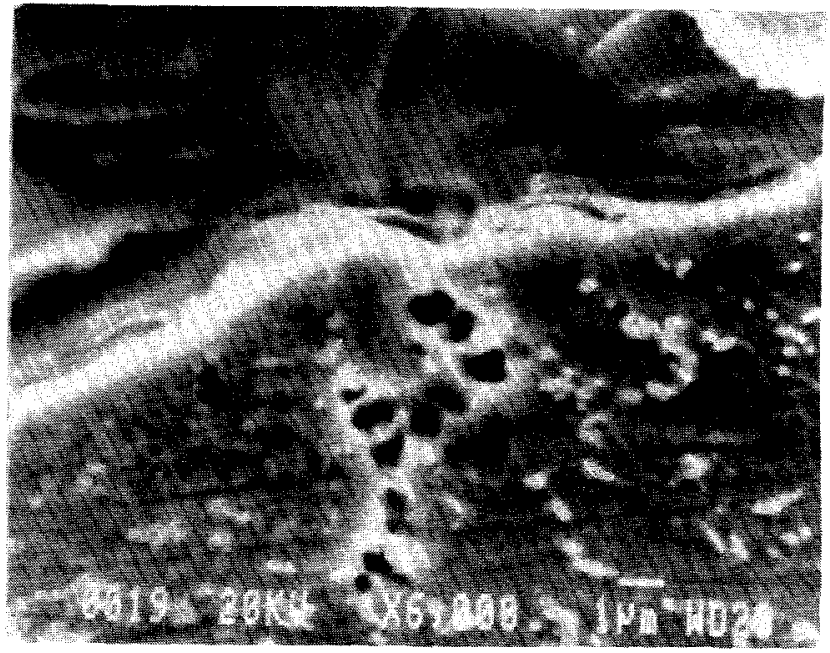

Figure 8 Section normal to fracture surface plane of Fig. 6 and $1 \mu \mathrm{m}$ from origin region of cleavage. Particles clinging to cavity sides are visible. The holes are incompletely joined

within a cluster of particles started two cleavage separations; one, moving (in the figure) downward and to the left; the other, at a higher level, moving forward and to the right. This behavior exposed a group of carbide particles similar to the particle clumps observed at cleavage origins within ICRs at loss-of-cleavage temperature.

In other examinations of cleavage initiation and reinitiation sites, the particle appearances differed considerably. At locations judged to be reinitiation locations, particularly within general cleavage regions, it seemed that debonding of single particles or particle pairs could be assisting the reinitiation event. The particle clumps associated with ICRs near loss-of-cleavage temperature would be expected to initiate cleavage also at lower temperatures. However, smaller particle arrays are more probable and can dominate as cleavage origins when either temperature reduction or high strain rate make their cleavage initiation severity adequate.

Nonuniformities that can cause a large elevation of local stress and local strain rate are present in heavy-section nuclear vessel materials. Examples are carbide banding, grain size variations, and grain boundary segregation. In addition, the precrack in a test specimen has crack-front irregularities that increase in size when hole-joining separation occurs before cleavage initiation. The cleavage initiation regions observed within ICRs were often close to 


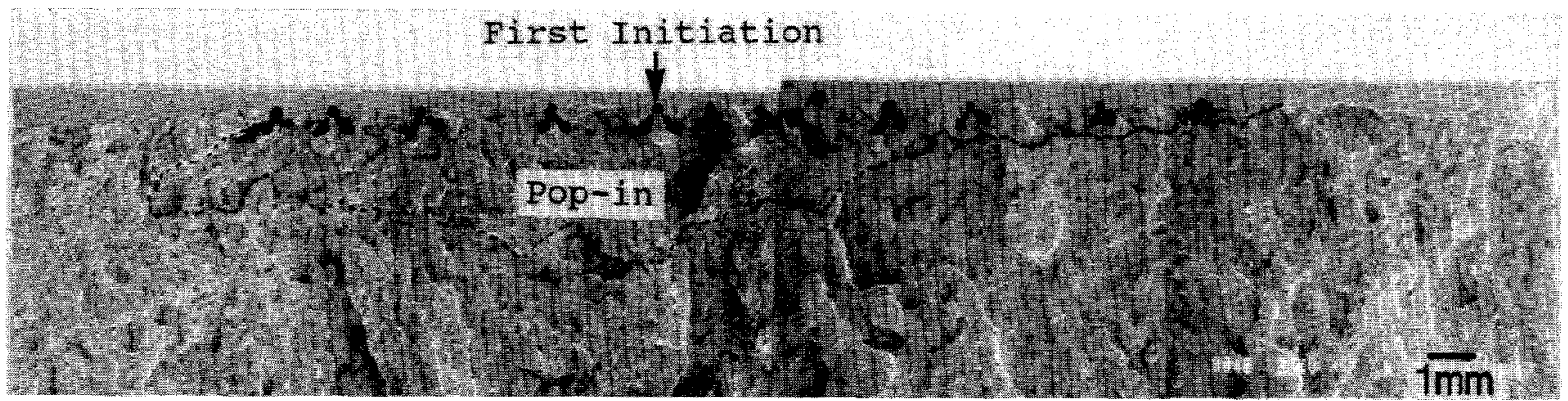

Figure 9 Regions of cleavage initiation at border of fatigue precrack as marked. The extent of a small pop-in event is also marked. The material was $A 08$ steel as in Figs. 6 and 7

ORNL-PHOTO 2620-94

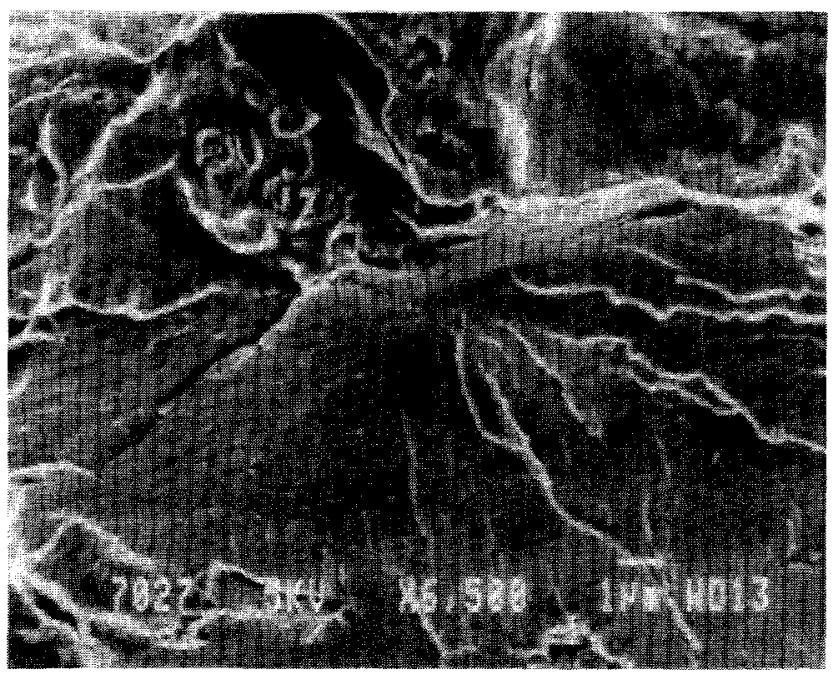

Figure 10 Cleavage initiation region judged likely to be first initiation event. Cleavage on two levels started from nest of cavities an ICR border with an adjacent region of hole-joining at the same level which had a relatively brittle appearance. The local stress-elevating events that cause a silicate particle to fracture rather than debond or cause a sufficient rapidity of debonding within a particle clump are not completely revealed by SEM viewing. However, varied degrees of assistance of that kind seem essential to an understanding of the "rare event" nature associated with cleavage initiation test results. Silicate particles ( 2 to $3 \mu \mathrm{m}$ in size) in low-carbon weld metal and particle clumps in the heavy-section steels are not rare. Their likelihood, per average ferrite grain volume, is substantial. ${ }^{6}$ Cleavage initiations become "rare" because particle fracture, rather than debonding, as well as an adequately high speed of debonding occur only with the aid of local stress elevations provided by other nonuniformities. 


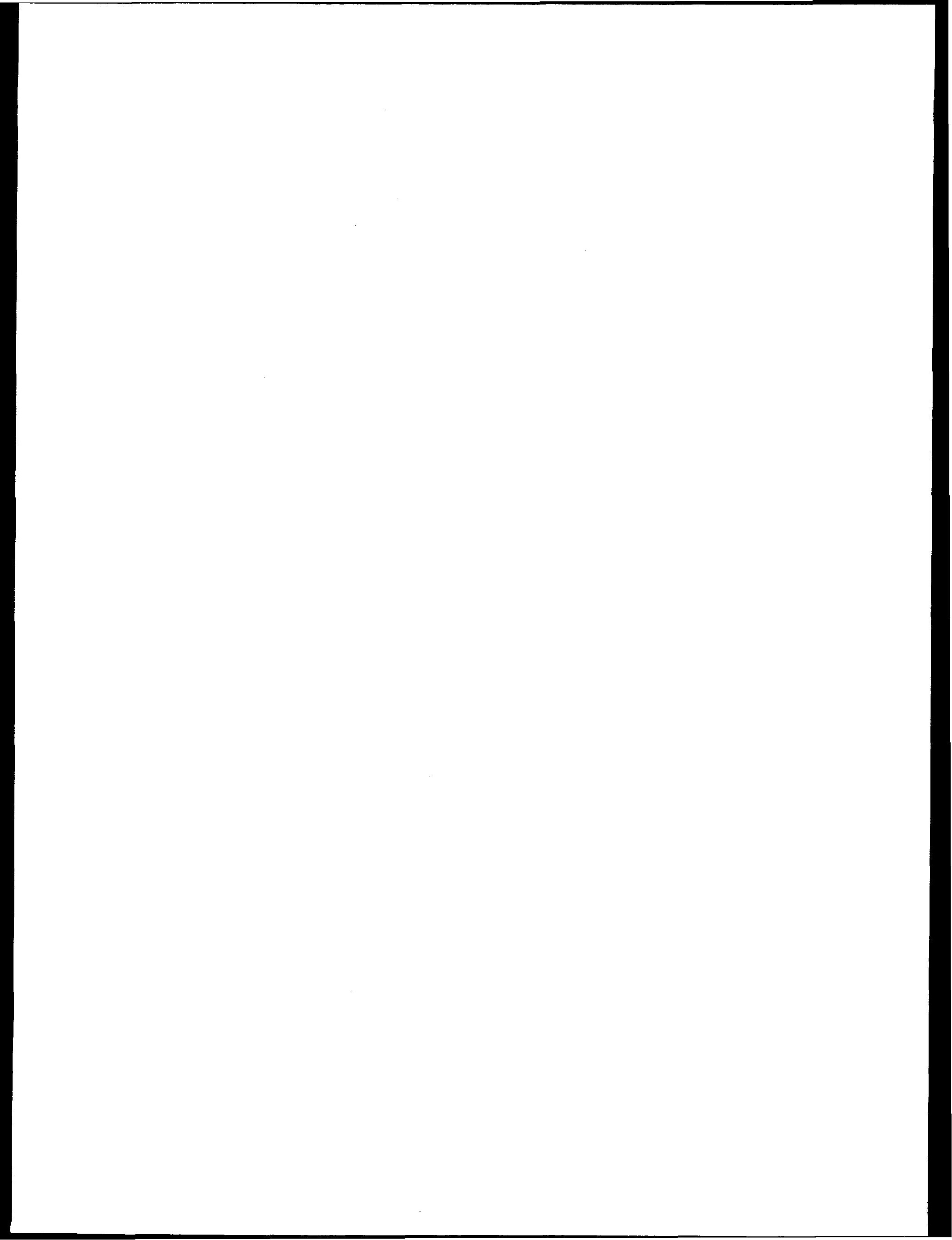




\section{Cleavage Embryos}

Among the features associated with cleavage behaviors in steels, the spreading of cleavage through ferrite grains is of major importance. For this nearly crystallographic event to occur, cleavage must start and spread from a nearly crystallographic cleavage embryo produced in some manner. Figure 11 shows potential origin locations for formation of cleavage embryos. For plausibility of occurrence, such an embryo must be quite small. However, it must be large enough so that the crack-extension driving force $G$ is as large as the resistance to spreading. Table 1 shows estimates of this size corresponding to assumed values of tensile stress $\sigma$ and of the resistance to spreading R. In the clumps of debonding carbide particles, which were cleavage origin locations, the particle size was in the 0.1 - to $0.2-\mu \mathrm{m}$ range. A cleavage embryo size larger than the particle size seems unlikely. From the table, the size corresponding to the smallest $R$ and the largest $\sigma$ seems best. Figure 12, from Ref. 2, shows values of plastic flow stress across a wide range of strain rates for $\alpha$-iron. Because the

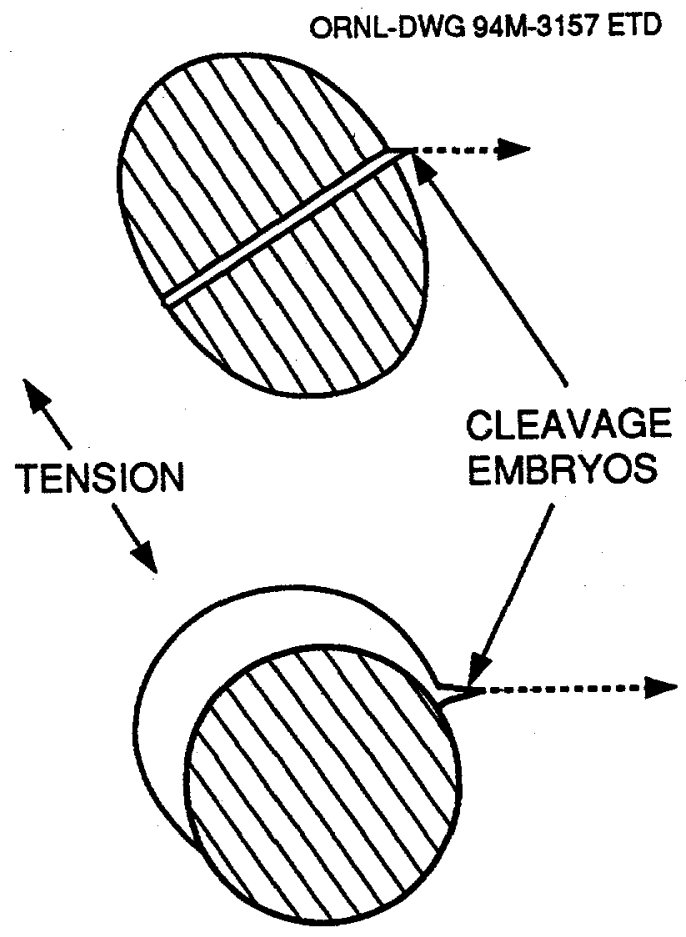

Figure 11 Schematic pictures of cleavage embryo formation steels of interest are stronger and local region strain rates applicable to Fig. 11 may be larger than $10^{5} / \mathrm{s}$, a local region stress high enough for the $0.12-\mu \mathrm{m}$ embryo size in Table 1 is plausible.

Table 1 Cleavage embryo size estimates for several values of local stress $\sigma$ and resistance to spreading $\mathbf{R}$

\begin{tabular}{ccc}
\hline$\sigma / E$ & $\begin{array}{c}\mathbf{a}(\mu \mathrm{m}) \\
\text { for } \mathbf{R}=\mathbf{2 0} \mathbf{J} / \mathbf{m}^{2}\end{array}$ & $\begin{array}{c}\mathbf{a}(\mu \mathrm{m}) \\
\text { for } \mathbf{R}=\mathbf{4 0} \mathbf{J} / \mathbf{m}^{2}\end{array}$ \\
\hline $1 / 40$ & 0.12 & 0.24 \\
$1 / 60$ & 0.27 & 0.55 \\
$1 / 80$ & 0.48 & 0.97 \\
\hline
\end{tabular}

Note: $G=\frac{4}{\pi}\left(\frac{\sigma^{2} a}{E}\right)$

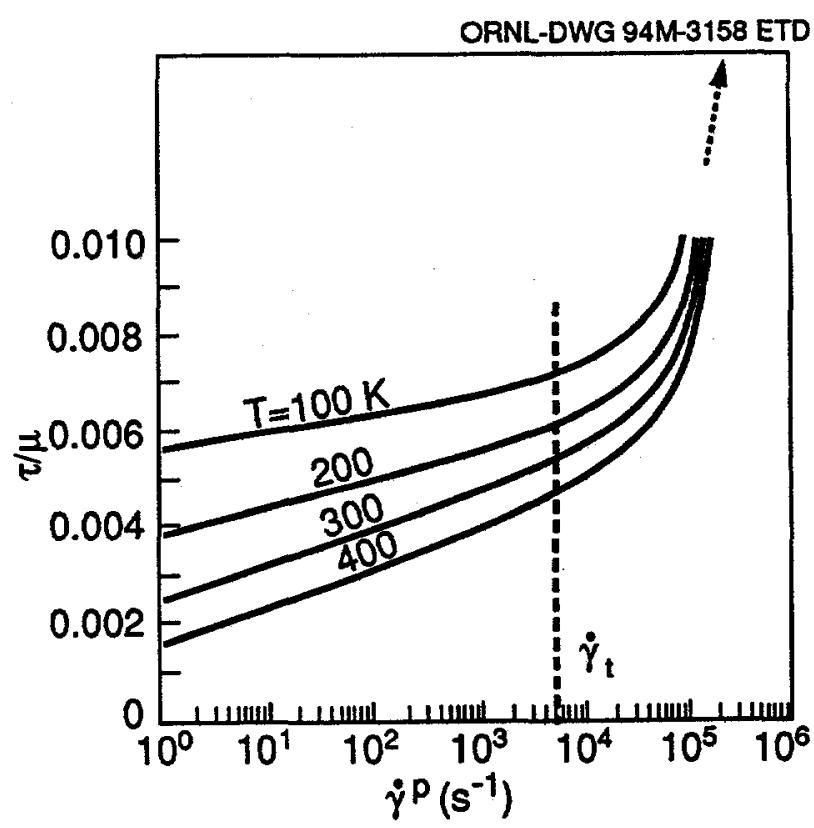

Figure 12 Stress as function of plastic strain rate at several temperatures for $\alpha$-iron (Ref. 2). Extrapolation toward $\Gamma=10^{6}$ as indicated 



\section{Summary and Conclusions}

In summary, a consistent understanding of the initiation, spreading, and arrest of cleavage in steels is possible only when the role of very high local strain rates is taken into account. Cleavage initiates only when the local strain rate is high enough to force a rigid (cleavage) response. The run-arrest bursts of cleavage through regions comparable to prior-austenite grain size correspond to fracture appearance and provide an explanation for variations of general cleavage crack speed. Cleavage crack-arrest toughness values are of special interest. They can be obtained using relatively small specimens, show no influence of constraint, and provide lower bounds for measurements of cleavage initiation toughness. 


\section{References}

1. J. M. Krafft and G. R. Irwin, "Crack Velocity Considerations" ASTM STP 381, 114-132 (1965)."

2. L. B. Freund and J. W. Hutchinson, "High Strain Rate Crack Growth in Rate Dependent Plastic Solids," J. of Mech. and Phys. of Solids, 33, 169-191 (1985)."

3. D. J. Naus et al., Martin Marietta Energy Systems, Inc. Oak Ridge National Laboratory, "Crack-Arrest Behavior in SEN Wide Plates of Low-Upper-Shelf Base Metal Tested Under Non-Isothermal Conditions, WP-2 Series," USNRC Report NUREG/CR-5451, August $1990 . \dagger$

4. D. B. Barker, R. Chona, W. L. Fourney, and G. R. Irwin, "A Report on the Round Robin Program Conducted to Evaluate the Proposed ASTM Standard Test Method for Determining the Plane Strain Crack Arrest Fracture Toughness, $\mathrm{K}_{\mathrm{Ia}}$, of Ferrite Materials," USNRC Report NUREG/CR-4996, January $1988 .{ }^{\dagger}$
5. G. R. Irwin, "Brittle-Ductile Transition Behaviors in Reactor Vessel Steels," pp. 251-272 in Proc. 14th WRSI Meeting, USNRC Conference Proceedings NUREG/CP 0082, Vol. 2, February 1987. ${ }^{\dagger}$

6. X. J. Zhang, A. Kumar, R. W. Armstrong, and G. R. Irwin, "Fractographic Study of Isolated Cleavage Regions in Nuclear Vessel Steels and Weld Metals," ASTM STP 1086, 89-101 (1990).*

7. X. J. Zhang, R. W. Armstrong, and G. R. Irwin, "Fractography of Isolated Cleavage Regions in Nuclear Vessel Steels," Metall. Trans., 20A, 2862$2868(1989){ }^{*}$

\footnotetext{
*Available in public technical libraries.

$\dagger^{\top}$ Available for purchase from National Technical Information Service, Springfield, VA 22161.
} 



\section{Internal Distribution}

$\begin{aligned} \text { 1. } & \text { D. J. Alexander } \\ 2-5 . & \text { B. R. Bass } \\ 6 . & \text { J. W. Bryson } \\ 7 . & \text { W. R. Corwin } \\ 8 . & \text { T. L. Dickson } \\ 9-10 . & \text { R. G. Gilliland } \\ \text { 11. } & \text { F. M. Haggag } \\ \text { 12. } & \text { W. F. Jackson } \\ \text { 13. } & \text { S. K. Iskander } \\ \text { 14. } & \text { J. A. Keeney } \\ \text { 15. } & \text { W.J. McAfee }\end{aligned}$

16. D. E. McCabe

17. J. G. Merkle

18. R. K. Nanstad

19-23. W. E. Pennell

24. C. E. Pugh

25. M. C. Rao

26. ORNL Patent Section

27. Central Research Library

28. Document Reference Section

29-30. Laboratory Records

31. Laboratory Records(RC)

\section{External Distribution}

32. J. W. Craig, Deputy Director, Division of Engineering, RES, U.S. Nuclear Regulatory Commission, Washington, DC 20555-0001

33. K. R. Wichman, Division of Engineering, NRR, U.S. Nuclear Regulatory Commission, Washington, DC 20555-0001

34. L. C. Shao, Director, Division of Engineering, RES, U.S. Nuclear Regulatory Commission, Washington, DC 20555-0001

35. T. P. Speis, Deputy Director, Office of Nuclear Regulatory Research, U.S. Nuclear Regulatory Commission, Washington, DC 20555-0001

36-38. S. N. M. Malik, Division of Engineering, U.S. Nuclear Regulatory Commission, Washington, DC 20555-0001

39. M. E. Mayfield, Division of Engineering, U.S. Nuclear Regulatory Commission, Washington, DC 20555-0001

40-44. G. R. Irwin, Department of Mechanical Engineering, University of Maryland, College Park, MD 20742

45. C. F. Shih, Box D, Division of Engineering, Brown University, Providence, RI 02912

46. R. Dodds, 3140 Newmark Laboratory, 205 North Matthews, Urbana, IL 61801

47. R. Fields, National Institute of Standards and Technology, Bldg. 223, B144, Gaithersburg, MD 20899

48. W. L. Fourney, Department of Mechanical Engineering, University of Maryland, College Park, MD 20742

49. S. T. Rolfe, The University of Kansas, Lawrence, KS 66045-2235

50. C. W. Schwartz, Department of Civil Engineering, University of Maryland, College Park, MD 20742

51-55. X. J. Zhang, Department of Mechanical Engineering, University of Maryland, College Park, MD 20742

56. Office of Assistant Manager for Energy Research and Development, DOE-ORO, Oak Ridge, TN 37831

57-58. Office of Scientific and Technical Information, P.O. Box 62, Oak Ridge, TN 37831

59. Y. J. Chao, Mechanical Engineering, The University of South Carolina, Columbia Campus, Columbia, SC 29208

60. T. L. Anderson, Department of Mechanical Engineering, Texas A\&M University, College Station, TX 77843

61. J. M. Joyce, U.S. Naval Academy, Annapolis, MD 21402 


\begin{tabular}{|c|c|}
\hline $\begin{array}{l}\text { U.S. NUCLEAR REGULATORY COMMISSION } \\
\text { BIBLIOGRAPHIC DATA. SHEET } \\
\text { (See instructions on the reverse) }\end{array}$ & $\begin{array}{l}\text { 1. REPORT NUMBER } \\
\text { (Axigned by NRC. Add Vol., Supp., Rov., } \\
\text { and Addendum Numbers, if onv.) } \\
\text { NUREG/CR-6262 } \\
\text { ORNL/SUb/79-7778/11 }\end{array}$ \\
\hline \multirow{4}{*}{$\begin{array}{l}\text { 2. TITLE AND SUBTITLE } \\
\text { Cleavage Behaviors in Nuclear Vessel Steels }\end{array}$} & \\
\hline & DATE REPORT PUBLISHED \\
\hline & \begin{tabular}{|c|r|} 
MONTH & YEAR \\
November & 1994 \\
\end{tabular} \\
\hline & $\begin{array}{l}\text { 4. FIN OR GRANT NUMBER } \\
\text { B0119 }\end{array}$ \\
\hline \multirow[t]{2}{*}{$\begin{array}{l}\text { 5. AUTHOR(S) } \\
\text { G. R. Irwin, X. J. Zhang }\end{array}$} & $\begin{array}{l}\text { 6. TYPE OF REPORT } \\
\text { Technical }\end{array}$ \\
\hline & 7. PERIOD COVERED (/Inc/usive Dates) \\
\hline
\end{tabular}

8. PERFORMING ORGANIZATION - NAME AND ADDRESS IIf NRC, provide Division, Office or Region, U.S. Nuclear Regulatory Commission, and mailing address; if contractor, provide name and mailing address.

Department of Mechanical Engineering Under Contract to:

University of Maryland

College Park, MD 20742

Oak Ridge National Laboratory

Oak Ridge, TN 37831-6285

9. SPONSORING ORGANIZATION - NAME AND ADDRESS "If NRC, type "Same as above"; if contractor, provide NRC Division, Office or Region, U.S. Nuclear Regulatory Commission, and malling address.).

Division of Engineering

Office of Nuclear Regulatory Research

U.S. Nuclear Regulatory Commission

Washington, DC 20555-0001

10. SUPPLEMENTARY NOTES

11. ABSTRACT (200 words or less)

Cleavage behaviors of nuclear vessel steels in the transition temperature range are reviewed. Viewpoints are presented to assist understanding of cleavage crack speed, cleavage initiation, cleavage arrest, and the sensitivity of fracture toughness to constraint and temperature. The importance of high local stress elevations by high strain rate is emphasized. This report is designated as HSST Report No. 149.

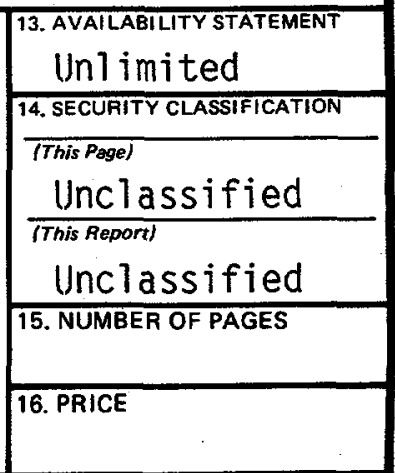

cleavage initiation

cleavage propagation

reactor pressure vessel

fractography

transition temperature

cleavage arrest

fracture toughness

initiation sites 